\title{
Identification of Recycled Cooking Oil by Varying Number of Au/GO Coated Fiber Optic's Loop Ring
}

\author{
Wan Maisarah Mukhtar ${ }^{*}$, Nur Fatin Liyana Manafi and Razman Mohd Halim² \\ ${ }^{1}$ Faculty of Science and Technology, Universiti Sains Islam Malaysia (USIM) Malaysia \\ ${ }^{2}$ National Metrology Institute of Malaysia (NMIM), SIRIM Berhad
}

\begin{abstract}
This study investigates the effect gold nanoparticles (Au)/graphene oxide (GO) coated fibre optics with various number of loop ring in identifying recycled cooking oil based on their frying time. Various layers of gold nanoparticles (AuNP) suspension were deposited onto the substrate via drop casting technique. Few material characterizations were performed such as Fourier Transform Infrared (FTIR) spectroscopy, Ultraviolet Visible (UV-Vis) spectroscopy and refractometer analysis. Three macrobending structures of Au/GO coated fiber optic's loop ring such as single, double and triple loops with diameter of $1.5 \mathrm{~cm}$ were formed to generate large area of evanescent field around the fibre and to excite surface plasmon polaritons due to the interaction between AuNPs and analytes. Cooking oil samples with different frying time such as 14 minutes, 28 minutes and 42 minutes were prepared as analytes. The FTIR analysis revealed some changes in the transmittance percent of some bands as well as some slight shifts in the exact position of the bands due to the different of fatty acid composition. As the Au/GO coated fibre optics were immersed into the samples, the penetration depths were obtained as $142.75 \mathrm{~nm}$ and $168.91 \mathrm{~nm}$ at operating wavelengths of $\lambda=1310 \mathrm{~nm}$ and $\lambda=155 \mathrm{Onm}$, respectively. By using $1550 \mathrm{~nm}$ operating wavelength due to its greater penetration depth than 1310nm, triple loop rings fibre optics coated with two layers of AuNP and one layer of GO exhibits a linear consistency with maximum sensitivity up to $69.17 \%$ due to the formation of large evanescent field around the loop area and intense SPP excitation.
\end{abstract}

Keywords: SPR; Au/GO; fibre optic sensor; recycled cooking oil; loop ring

\section{INTRODUCTION}

The usage of cooking oil in food production has effects to human's health if consumed regularly. The degree of saturation of fatty acids is the most crucial factor in deciding the oil's resistance to oxidation and staleness. Oxidation causes the form of free radicals that can damage cells and lead to cancer. Free radical levels that exceeds the produced antioxidant will cause oxidative stress (Bogoriani \& Sudiarta, 2016). Oxidative stress is an imbalance between the production and detoxification of reactive oxygen species (Münzel et al., 2017). Reusing cooking oil induces a change of physical and chemical properties such as the formation of toxic compound such as 4-hydroxy-trans-2-nonenal (HNE).
Consuming cooking oil containing HNE can contribute to cardiovascular disease, stroke, Alzheimer's disease, Parkinson's disease, various liver complications as well as cancer diseases (Ishak et al., 2016).

Plant extraction produces oils or fats that are commonly known as vegetable oils. Most of the oils can be used for cooking oil or for fuel production. There are various types of vegetable oils such as palm oil, sunflower seed oil, canola oil, soybean oil and many more. Vegetable oils are commonly used in food production as they contain more unsaturated fatty acids compared to animal fats. Vegetable oils or cooking oils are used in preparing food especially frying. The quality assurance of cooking oil is important as to prevent the 
formation of toxic compounds and the loss of nutritional components (Hosseini et al., 2016). At high temperature, lipid reaction such as hydrolysis, oxidation and thermal alteration are occurred during heating of cooking oil. Dobarganes and Marquez-Ruiz (2015) stated that there are many resulting compounds of hydrolysis, oxidation and thermal alteration that will increase the rate of degradation of cooking oil.

Recently, various types of sensors have been rapidly developed for food security applications. Surtono et. al (2018) designed a measuring instrument for cassava starch content using a strain gauge sensor as a weight gauge. Electrochemical sensor is one of the alternative methods for food safety inspection (Jingna \& Yang 2017; Maduraiveeran et. al., 2017; Mishra et al., 2018). Lately, better sensitivity and less complicated structure of optical sensor attracts researcher to employ this light based sensor in various applications including food safety area (Cocola et. al., 2019; Pechprasarn et. al., 2019; Semeano et al., 2018). The optical sensor can be categorised into two types, such as fibre optics based sensor (Ascorbe et. al., 2017; Kamarulzaman et. al., 2020; Mukhtar et. al., 2012; Ascorbe et al., 2017) and free space optics based sensor (Gan et. al., 2019; Mukhtar et. al., 2019; Smith et al., 2017). Surface plasmon resonance (SPR) were found able to enhance the sensitivity of the sensor by excited surface plasmon polaritons to enhance the strength of evanescent field. This phenomenon can be created with the interaction between TM polarized light and noble metal. Gold $\mathrm{Au}$ ) and silver $\mathrm{Ag}$ ) have been proved as the best materials to generate maximum plasmonic effect (Mukhtar et. al., 2017a; Mukhtar et. al., 2018b; Wang et. al., 2018; Zhao et al., 2018). There are few factors that affect the optimization of SPR signal namely light wavelength, metal thin film's thickness, physical structure of prism, size and structure of nanoparticles and the introduction of materials (Mukhtar et. al., 2013; Mukhtar et. al., 2017b; Murat et. al., 2016; Usha et al., 2016).

The penetration depth of the fibre can be calculated as shown in the following Equation (1) where $\lambda$ is the vacuum wavelength of the light launched into the fibre, $n_{1}$ and $n_{2}$ are the refractive index of the core and analytes, respectively. $\theta_{c}$ is critical angle in the sensing region with respect with the normal to the core-cladding interface, $\theta$ is the angle of the wave with the normal to the core-cladding interface, $\theta_{\varnothing}$ and is the skewness angle (Rashid et al., 2020).

$$
d_{p}=\frac{\lambda}{2 \pi n_{1}\left(\cos ^{2} \theta_{c}-\cos ^{2} \theta \sin ^{2} \theta_{\emptyset}\right){ }^{1 / 2}}
$$

This study presents the utilization of SPR phenomenon to detect the quality of cooking oil by using a macrobend fibre optics. The loop ring fibre optics has been coated with gold nanoparticles (AuNP) to excite surface plasmon polaritons (SPP). Various stages of recycled oil samples have been prepared by immersed the sensor into the samples that had been heated with different frying time. The output of this work exhibits the potential of SPR based macrobent fibre optic sensor to identify the recycled cooking oil. We believe this research outcome will benefit to the society in food safety area.

\section{MATERIALS AND METHOD}

The jacket and polymer coating of standard optical communication single mode fibres (SMF) were removed by using optical fibre stripper. Three loop ring structures of fibre optics with various number of loops, such as single loop, double loops and triple loops were formed by bending the SMF into $1.5 \mathrm{~cm}$ in diameter. The bending fibre structure is believed will generate the evanescent waves propagation. Figure 1 shows the schematic diagram of macrobent SMF with various number of loop rings. The proposed sensor utilizes the undesirable loss, e.g. bending loss as sensing mechanism by allowing the perturbation (acoustic vibration) to induce optical power losses through the bend fibres. Such losses are associated with the random change in the radius of bending

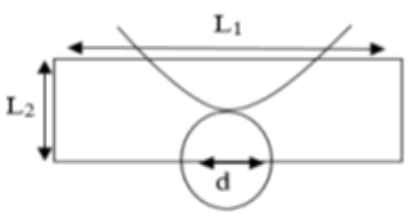

(i)

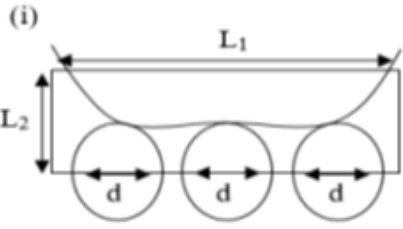

(iii)

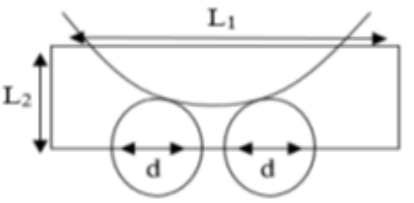

(ii)
Figure 1. Schematic diagram of macrobent fiber optics with various number of loop rings (i) single loop, (ii) double loops, (iii) triple loops, where $\mathrm{d}=1.5 \mathrm{~cm}, \mathrm{~L} 1=7.5 \mathrm{~cm}$ and $\mathrm{L} 2=2.5 \mathrm{~cm}$. 
due to applied force or displacement (Ong et al., 2017). When the single-mode fiber is bent, transition loss will arise due to the mode conversion from fundamental mode to leaky clad mode where light transmission at the outer part of the curvature is travel faster than the inner part which has smaller inner radius (Keiser 2008; Kamarulzaman et al. 2020). The unjacketed area was coated with gold nanoparticles, AuNP (diameter, $\mathrm{d}=5 \mathrm{0nm}$ ) and graphene oxide (GO) by using a drop casting technique. This technique was performed by deposited $50 \mu \mathrm{L}$ of AuNP in which was dispersed in $\mathrm{H}_{2} \mathrm{O}$ onto the bent region by using a micropipette. The coated area was left dry for approximately 3 hours at room temperature. This step was repeated by adding the number of AuNP layer from one to three layers. Next, $50 \mu \mathrm{L}$ of GO (Brand: Graphenea) with 2.5 wt\% concentration was coated onto the AuNP layer and let dry for approximately 12 hours at room temperature. In this study, the GO layer was fixed at one layer only. Note that, too thick of GO layer will result the absorption of SPP which will decrease the sensing ability of our proposed sensor (Mukhtar et. al., 2018a; Murat et al., 2020). The optical properties of $\mathrm{Au}$ and GO were characterized by using UV-Vis spectrometer. The loop ring $\mathrm{Au} / \mathrm{GO}$ coated fibre optics was glued onto the glass slide. The glass slide acted as a sensor holder.

The recycled cooking oil samples were prepared by deep fried $100 \mathrm{~g}$ of potato fries in a cooking palm oil (Brand: Saji, manufacturer: Delima Oil Products Sdn. Bhd) with a different number of cooking cycles. About $20 \mathrm{ml}$ of cooking oil samples were collected for each frying time, approximately about 14 minutes per cycle. The digital refractometer was used to determine the refractive index of the samples. Each sample was characterized by using Fourier Transform Infrared (FTIR) spectroscopy to determine the composition and existence of specific functional groups. All spectra were measured at region from $4000 \mathrm{~cm}^{-1}$ to $650 \mathrm{~cm}^{-1}$. Four samples of recycled cooking oil were prepared as listed in Table 1.
Table 1. Description of recycled cooking oil's samples

\begin{tabular}{cc}
\hline Sample & Description \\
\hline 1 & New cooking oil \\
2 & 14 minutes of frying time \\
3 & 28 minutes of frying time \\
4 & 42 minutes of frying time \\
\hline
\end{tabular}

Figure 2 illustrates an experimental setup of loop ring $\mathrm{Au} / \mathrm{GO}$ coated fibre optics for recycled cooking oil identification. The evanescent field and excitation of surface plasmon polaritons (SPP) were generated by connecting the loop ring $\mathrm{Au} / \mathrm{GO}$ coated fibre optics with infrared (IR) laser source with wavelength of $\lambda=1310 \mathrm{~nm}$ and $\lambda=1550 \mathrm{Om}$ (Brand: Noyes). The output signal was measured by using an optical power meter (Brand: Noyes). The Au/GO coated sensing region was then immersed in the cooking oil samples. The identification of recycled cooking oil was studied by varying the number of loop ring and $\mathrm{Au}$ layer of the $\mathrm{Au} / \mathrm{GO}$ macrobent SMF. Throughout this work, the optimized structure of our proposed sensor had been investigated based on percentage of optical power changes as the sensor exposed to the samples.

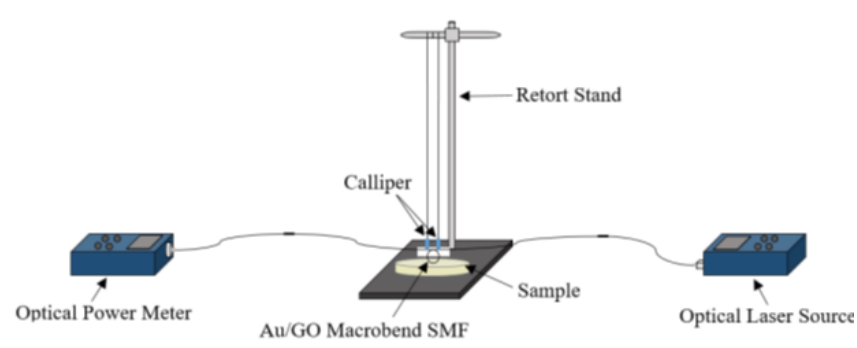

Figure 2. Schematic diagram of loop ring Au/GO coated fiber optics to identify recycled cooking oil

\section{RESULTS AND DISCUSSIONS}

All samples showed similar colour based on naked-eye visual observation. Refractive indices for each sample were slightly difference due to oxidization as recorded by the digital refractometer, as shown in Table 2. As the loop ring of the $\mathrm{Au} / \mathrm{GO}$ coated fibre optics were immersed into the samples, the penetration depths were obtained as $142.75 \mathrm{~nm}$ and $168.91 \mathrm{~nm}$ at operating wavelengths of $\lambda=1310 \mathrm{~nm}$ and $\lambda=1550$ nm, respectively. As stated in Equation (1), the penetration depth is influenced by the refractive index of core 
and medium. In this study, the penetration depth values for each wavelength at different refractive indices were similar since no distinct differences had been observed on the value of refractive index's samples.

Table 2. Refractive index of recycled cooking oil and the penetration depth of proposed sensor

\begin{tabular}{|c|c|c|c|}
\hline \multirow[t]{2}{*}{ Sample } & \multirow{2}{*}{$\begin{array}{c}\text { Refractive } \\
\text { index }\end{array}$} & \multicolumn{2}{|c|}{ Penetration depth, $d_{p}(\mathrm{~nm})$} \\
\hline & & $\lambda=1310 \mathrm{~nm}$ & $\lambda=1550$ mm \\
\hline 1 & 1.4653 & \multirow{4}{*}{142.75310} & \multirow{4}{*}{168.90634} \\
\hline 2 & 1.4654 & & \\
\hline 3 & 1.4655 & & \\
\hline 4 & 1.4655 & & \\
\hline
\end{tabular}

According to the FTIR analysis, the cooking oil samples displayed indistinguishable patterns without distinct differences, except for intensities or peak areas as shown in Figure 3. A close interpretation of the spectra revealed that there are some changes in the transmittance percent of some bands as well as some slight shifts in the exact position of the bands. This change proposes that the oil composition has effects on the exact position of the bands and shifts in the bands when the fatty acid composition is changed.
Sample 1

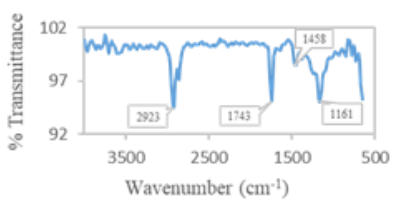

(a)

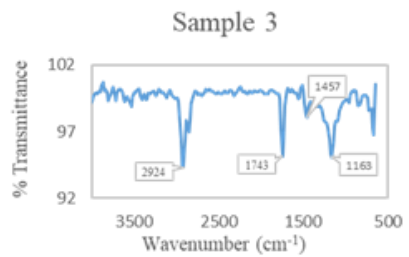

(c)
Sample 2

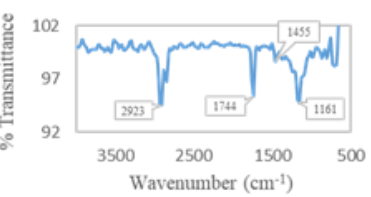

(b)

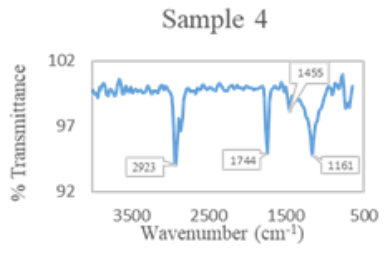

(d)

Figure 3. FTIR spectra for sample 1, 2, 3 and 4

Small changes of peak for each oil samples were resulted due to the changes of cooking oil's composition resulted from frying time (Table 3). The absorption bands at 2923-2924 $\mathrm{cm}^{-1}$ were due to the stretching vibration of the hydroxyl group (vO-H). The absorption bands at $1743-1744 \mathrm{~cm}^{-1}$ because of the stretching vibration of $\mathrm{vC}=\mathrm{O}$ and $\mathrm{vC}=\mathrm{C}$, or by the in-plane bending vibration of $\delta \mathrm{N}-\mathrm{H}$, showing the presence of carboxylic acid, fatty ketone, or amino groups functional groups. The peaks at $1161-1163 \mathrm{~cm}^{-1}$ were recognized to the $\mathrm{vC}-\mathrm{O}$ stretching vibrations, which are

Table 3. Major peaks observed from FTIR spectra of cooking oil samples

\begin{tabular}{|c|c|c|c|c|}
\hline Functional group & Sample 1 & Sample 2 & Sample 3 & Sample 4 \\
\hline $\begin{array}{l}\text { C-H stretching band (hydroxyl group } \\
(\mathrm{vO}-\mathrm{H}))\end{array}$ & $2923 \mathrm{~cm}^{-1}$ & $2923 \mathrm{~cm}^{-1}$ & $2924 \mathrm{~cm}^{-1}$ & $2923 \mathrm{~cm}^{-1}$ \\
\hline $\begin{array}{l}\mathrm{C}=\mathrm{O} \text { stretching band (carboxylic acid, } \\
\text { fatty ketone, or amino groups } \\
\text { functional groups) }\end{array}$ & $1743 \mathrm{~cm}^{-1}$ & $1744 \mathrm{~cm}^{-1}$ & $1743 \mathrm{~cm}^{-1}$ & $1744 \mathrm{~cm}^{-1}$ \\
\hline $\begin{array}{l}\text { Bending vibrations of } \mathrm{CH}_{2} \text { and } \mathrm{CH}_{3} \\
\text { aliphatic groups }\end{array}$ & $1458 \mathrm{~cm}^{-1}$ & $1455 \mathrm{~cm}^{-1}$ & $1457 \mathrm{~cm}^{-1}$ & $1455 \mathrm{~cm}^{-1}$ \\
\hline $\begin{array}{l}\text { C-O stretching vibrations (hydroxyl, } \\
\text { ester, and ether functional groups) }\end{array}$ & $1161 \mathrm{~cm}^{-1}$ & $1161 \mathrm{~cm}^{-1}$ & $1163 \mathrm{~cm}^{-1}$ & $1161 \mathrm{~cm}^{-1}$ \\
\hline
\end{tabular}

resulted from the hydroxyl, ester, and ether functional groups (Alshuiael \& Al-Ghouti, 2020). AuNPs demonstrate a discrete optical characteristic usually known as localized surface plasmon resonance (LSPR), that is, the cumulative oscillation of electrons in the conduction band of AuNPs in resonance with a particular wavelength of incident light. Figure 4 shows the optical absorbance properties of AuNPs as the nanoparticles' suspension were deposited at 1 layer (single drop), 2 layers (two drops) and 3 layers (three drops) on the glass slide against the wavelength ranges between $300 \mathrm{~nm}$ to $800 \mathrm{~nm}$. Obviously, LSPR of AuNPs resulted in a strong absorbance band in the visible region around $500 \mathrm{~nm}$ to 600 $\mathrm{nm}$ in which indirectly verified the presence of AuNPs on the substrate via drop-casting deposition technique. The maximum optical absorbance peak for GO were found around $286 \mathrm{~nm}$ to $296 \mathrm{~nm}$ as illustrated in Figure 5, in which shows an excellent agreement with previous studies (Samsuri et al., 2017). 


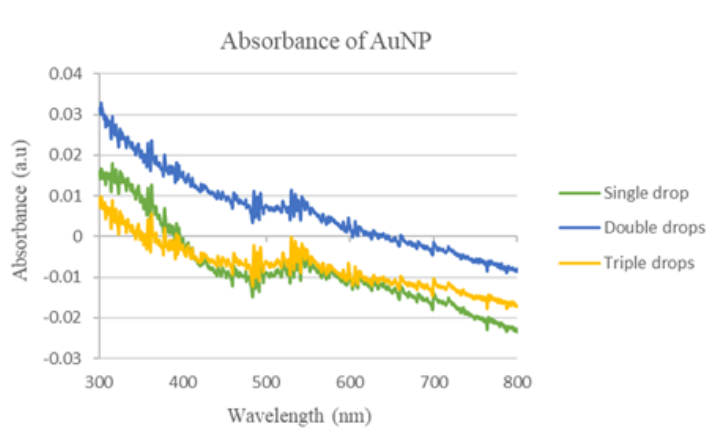

Figure 4. The optical absorbance properties of one, two and trilayers of AuNPs against the wavelength ranges between $300 \mathrm{~nm}$ to $800 \mathrm{~nm}$

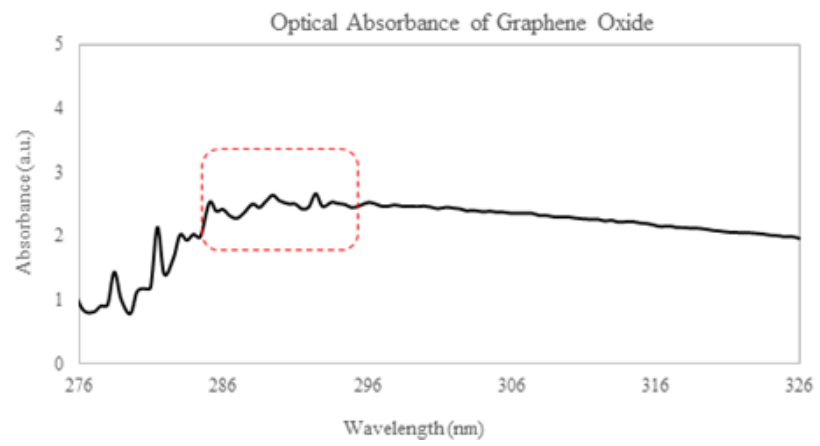

Figure 5. The optical absorbance properties of GO against with maximum absorption between wavelength of $286 \mathrm{~nm}$ to $296 \mathrm{~nm}$

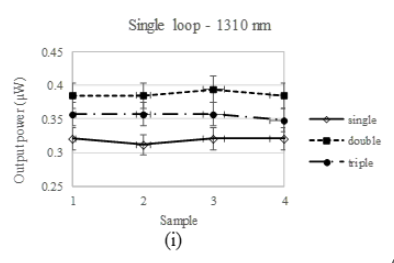

(a)

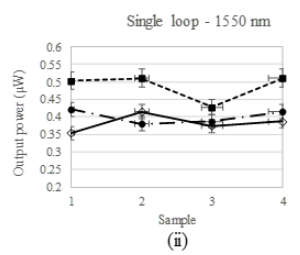

$\rightarrow \rightarrow-\rightarrow$ ingle
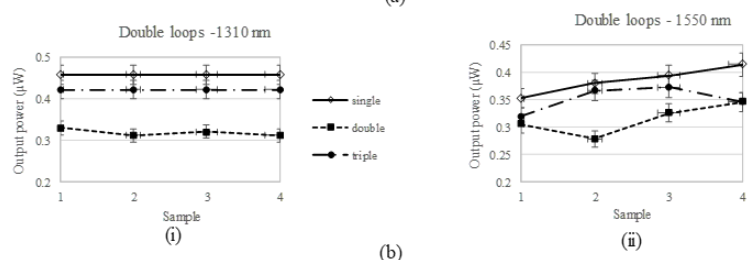

(ii)
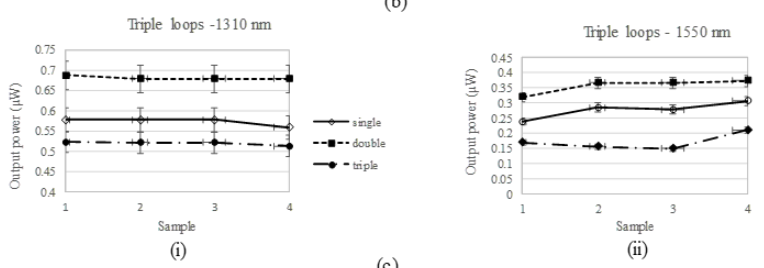

Figure 6. Optical output power against various samples of recycled cooking oil detected by loop rings $\mathrm{Au} / \mathrm{GO}$ coated fibre optics (a) single loop, (b) double loops and (c) triple loops
Figure 6 presents the characteristics of optical power output against various types of cooking oil detected by Au/GO coated fibre optics sensor with numerous number of loop ring such as single loop, double loops and triple loops. The number of Au layers and excitation wavelength's values were also manipulated to determine the optimum structure to produce high sensitivity sensor. The deployment of sensor with operating wavelength at $1550 \mathrm{~nm}$ resulted better sensitivity than 1310 m since less attenuation occurred at 1550nm (Kamarulzaman \& Mukhtar, 2020). This condition could be apparently noticed by unobvious differences of output power when the operating wavelength was set at $1310 \mathrm{~nm}$. The output of this analysis indicates that $1310 \mathrm{~nm}$ is unsuitable to be appointed as light source since the sensor cannot differentiate various types of analytes (Figure 6(a)(i), (b)(i) and c(i)). As lights source was changed to $1550 \mathrm{~nm}$, the value of optical output power shows a good response as the sensor exposed to the various stage of recycled cooking oil represented by the apparent changes of output power (Figure 6(a)(ii), (b)(ii) and c(ii)).

Sensitivity analyses were performed by determined normalised percentage difference of optical power changes before and after exposed to the samples as illustrated in Figure 7. The greater the changes, the better the sensitivity of sensor (Mukhtar et al., 2020). The employment of single and triple loop rings of $\mathrm{Au} / \mathrm{GO}$ coated fibre optics shows an excellent sensitivity of sensor by using $1550 \mathrm{~nm}$ light source (Figure 7(a) and (c)). Based on the analysis, we found that the sensor's sensitivity can be optimized by using triple loop rings fiber optics coated with two layers of 50nm in diameter of AuNPs. This condition can be explained by considering the enhancement of evanescent field's strength due to the surface plasmon resonance and the macrobending effect as few numbers of loop ring were introduced in this study (Mukhtar et. al., 2020; Murat et al., 2020). Note that the intensity enhancement of evanescent field resulted from the strong excitation of evanescent waves due to the triple macrobending of three loops SMF increased the penetration depth area of the sensor (Kamarulzaman \& Mukhtar, 2020).

Figure 8 describes the sensing characteristics of triple loop rings $\mathrm{Au} / \mathrm{GO}$ coated fibre optics with two layers of AuNP using $1550 \mathrm{~nm}$ wavelength of laser source. Note that, the optical power differences increased linearly with the 
increment of frying time. Recycled cooking oil contains more saturated fatty acids than new cooking oils. Heated cooking oil has poor quality due to saturated fatty acid content (Sugito \& Firdausi 2018). The relationship can be expressed as $\Delta \mathrm{P}=18.57 \mathrm{x}$. When the sensor was exposed to the new cooking oil, the optical power changed about 20.53\%. The sensor detected about $25.56 \%$ power change as it was immersed into the recycled cooking oil that was used to deep fry food for 14 minutes. After 28 minutes of frying time, the percentage of power change resulted $68.77 \%$. About $69.17 \%$ of power change was observed as the triple loop rings of Au/GO coated fibre optics was dipped into sample 4 (42 minutes of frying time). This analysis proves the selectivity capability of the

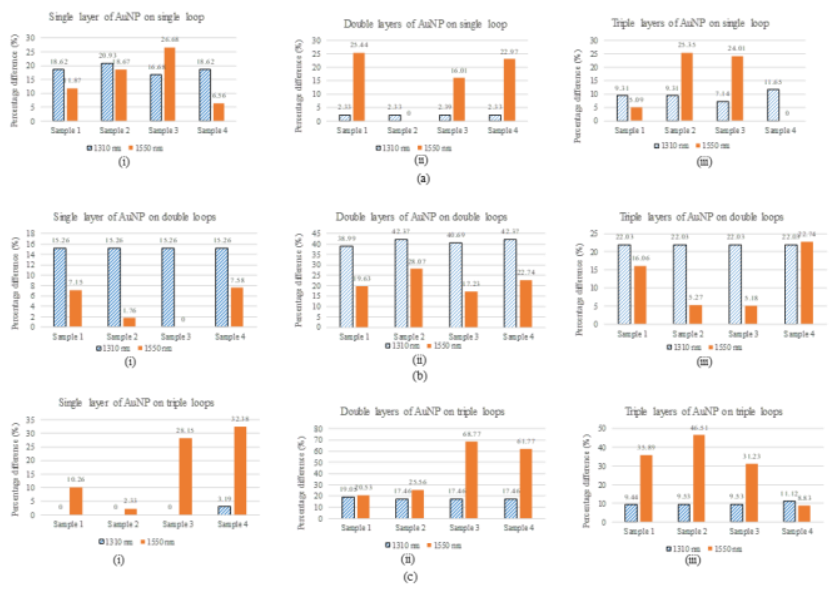

Figure 7. Percentage difference of optical power output with various number of loop (a) single, (b) double and (c) triple

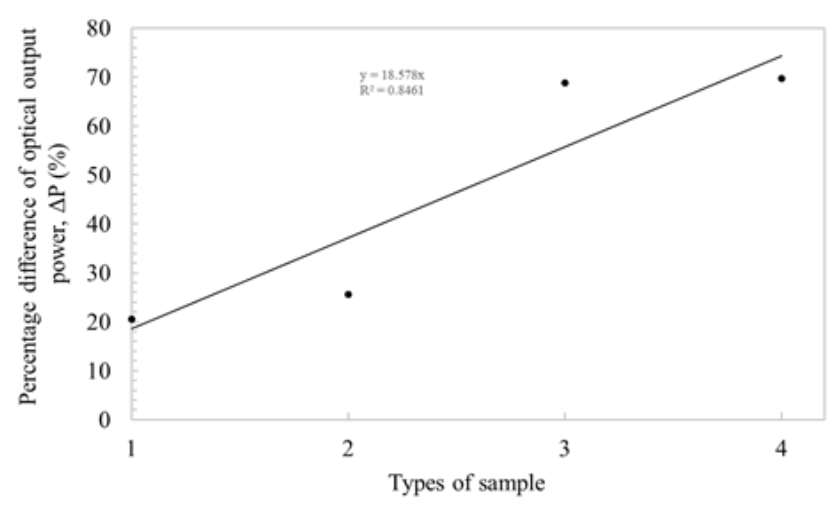

Figure 8. Percentage difference of optical power output for optimized Au/GO triple loops macrobend SMF sensor using two AuNP layers for quality assessment of used cooking oil samples

proposed sensor in detecting different samples of recycled cooking oils based on the amount of percentage power changes. Note that, higher refractive index of sample was produced when duration of frying time increased. This condition occurred due to the presence more saturated fatty acids in recycled cooking oil. Small portion of light was radiated away from the fibre due to light leakage. This condition caused part of light was absorbed by the cooking oils resulted changes in output power. Excellent sensing properties were observed with the deployment of triple loop rings of $\mathrm{Au} / \mathrm{GO}$ fibre optics due to the stronger evanescent field produced around the bent area. Larger coverage region of evanescent field resulted intense sensing area. The excitation of SPP were successfully enhanced by employed two layers of AuNPs. SPR with collective oscillation of electrons on the interface of metal/dielectric, detected the change of refractive index near the sensing surface, which is cooking oil. The recycled cooking oil interacted with the AuNPs, which caused the change of refractive index near the sensing surface. Since we used AuNP suspension, it was difficult to ensure that all macrobent region of fibre optics were uniformly coated by these metal nanoparticles. By adding another layer of AuNPs, the number of particles coated on the fibre increased. However, one layer of GO was sufficient to amplify the SPR signal and also acted as resistance layer to avoid oxidization of noble metal.

\section{CONCLUSION}

This study proposed an alternative approach to identify the recycled cooking oil. A high sensitive $\mathrm{Au} / \mathrm{GO}$ coated fibre optics sensor was successfully developed by using triple loop rings of fiber, which had been coated with two layers of $\mathrm{Au}$ (50nm in diameter) and one layer of GO. The linear relationship between the increment of frying time and optical output power indicates the excellent consistency and selectivity of the sensor with maximum sensitivity of $69.17 \%$. Combination of strong excitation of SPR due to light interaction between AuNPs and analytes and wide evanescence field region around fibre optics produced by the triple loop rings resulted excellent sensitivity sensor. The output of this study portrays the potential of loop ring Au/GO coated fibre optics in identifying recycled cooking oil samples based on optical technique by employing low cost and simple fabrication technique. 


\section{ACKNOWLEDGEMENT}

The Faculty of Science and Technology, USIM is acknowledged for the research facilities and undergraduate final year project (FYP) allocation to the second author.

\section{REFERENCES}

Ascorbe, J, Corres, JM, Arregui, FJ, \& Matias, IR 2017, "Recent developments in fiber optics humidity sensors". Sensors, vol. 17, no. 4, pp. 893.

Alshuiael, SM \& Al-Ghouti, MA 2020, 'Multivariate analysis for FTIR in understanding treatment of used cooking oil using activated carbon prepared from olive stone', Plos one, vol. 15, no. 5, pp. e0232997.

Bogoriani, NW \& Sudiarta, IW 2016, 'Effect of used cooking oil of the stress oxidative and inflammation on wistar rats', Biomedical and Pharmacology Journal, vol. 9, no. 10, pp. 899-907.

Cocola, L, Fedel, M, Franzoi, M, Goi, A, De Marchi, M, \& Poletto, L, 2019, April, 'Development and validation of a multi gas optical sensor for the meat industry', in Sensing for Agriculture and Food Quality and Safety XI (vol. 11016, pp. 1101607), International Society for Optics and Photonics.

Dobarganes, C, \& Márquez-Ruiz, G 2015, 'Possible adverse effects of frying with vegetable oils', British Journal of Nutrition, vol. 113, no. S2, pp. S49-S57.

Gan, NNGMA, Taib, NAM, Abdullah, M, Mukhtar, WM \& Rashid, ARA 2019, November, 'Uric acid detection by using contactless intensity modulation based displacement sensor', in Journal of Physics: Conference Series (vol. 1371, no. 1, pp. 012020), IOP Publishing.

Hosseini, H, Ghorbani, M, Meshginfar, N, \& Mahoonak, AS 2016, 'A review on frying: procedure, fat, deterioration progress and health hazards', Journal of the American Oil Chemists' Society, vol. 93, no. 4, pp. 445-466.

Ishak, AJ, Abdul Rahman, RZ, Soh, AC, Shamsudin, R, Jalo, SA, Lim, FC, \& Lin, HK 2016, 'Quality identification of used cooking oil based on feature fusion of gas sensor and color', International Journal of Control Theory and Applications, vol. 9, no. 5, pp. 2405-2413.
Jingna, S \& Yang, S 2017, 'Application of improved electrochemical sensor in food safety inspection', Chemical Engineering Transactions, vol. 59, pp. 721-726.

Kamarulzaman, AH, \& Mukhtar, WM 2020, 'Hybrid Ushaped-microbend smf evanescent wave sensor for river water quality assessment: a preliminary study', Science Letters, vol. 14, pp. 1.

Keiser, G 2008, Optical Fiber Communications, McGraw-Hill Education, India.

Maduraiveeran, G, \& Jin, W 2017, 'Nanomaterials based electrochemical sensor and biosensor platforms for environmental applications', Trends in Environmental Analytical Chemistry, vol. 13, pp. 10-23.

Mishra, GK, Barfidokht, A, Tehrani, F, \& Mishra, R K 2018, 'Food safety analysis using electrochemical biosensors', Foods, vol. 7, no. 9, pp. 141.

Mukhtar, WM, Menon, PS, \& Shaari, S 2012, 'Effect of taper angle of the optical fiber microprobe in power collection', in Advanced Materials Research (vol. 403, pp. 3387-3391), Trans Tech Publications Ltd.

Mukhtar, WM, Shaari, S, \& Menon, PS 2013, 'Influences of light coupling techniques to the excitation of surface plasmon polaritons', Advanced Science Letters, vol. 19, no. 1, pp. 66-69.

Mukhtar, WM, Halim, RM, Dasuki, KA, Rashid, ARA, \& Taib, NAM 2017, 'SPR sensor for detection of heavy metal ions: manipulating the EM waves polarization modes', Malaysian Journal of Fundamental and Applied Sciences, vol. 13, no. 4, pp. 619-622.

Mukhtar, WM, Halim, RM, \& Hassan, H 2017, 'Optimization of SPR signals: monitoring the physical structures and refractive indices of prisms', in EPJ Web of Conferences (vol. 162, pp. 01001), EDP Sciences.

Mukhtar, WM, Ahmad, FH, Samsuri, ND, \& Murat, NF 2018, June, 'Study on plasmon absorption of hybrid Au-GO-GNP films for SPR sensing application', in AIP Conference 
Proceedings (vol. 1972,no. 1, pp. 030007), AIP Publishing LLC.

Mukhtar, WM, Halim, RM, Dasuki, KA, Rashid, ARA, \& Taib, NAM 2018, August, 'Silver-graphene oxide nanocomposite film-based SPR sensor for detection of Pb 2+ ions', in 2018 IEEE International Conference on Semiconductor Electronics (ICSE) (pp. 152-155), IEEE.

Mukhtar, WM, Zulkifli, NZM, \& Halim, RM 2019, 'Identification of near-field and far-field using confocal microscopy setup for optical sensing applications', ASM Science Journal, vol. 5, pp. 1-8.

Mukhtar, WM, Latib, SN, Halim, RM, \& Rashid, ARA 2020, 'Graphene based macrobend unclad SMF for monitoring $\mathrm{pH}$ level in aqueous environment', in Solid State Phenomena (vol. 307, pp. 78-83), Trans Tech Publications Ltd.

Münzel, T, Sørensen, M, Gori, T, Schmidt, FP, Rao, X, Brook, J \& Rajagopalan, S 2017, 'Environmental stressors and cardio-metabolic disease: part I-epidemiologic evidence supporting a role for noise and air pollution and effects of mitigation strategies', European Heart Journal, vol. 38, no. 8 , pp. 550-556.

Murat, NF, Mukhtar, WM, Rashid, ARA, Dasuki, KA, \& Yussuf, AARA 2016, August, 'Optimization of gold thin films thicknesses in enhancing SPR response', in 2016 IEEE International Conference on Semiconductor Electronics (ICSE) (pp. 244-247), IEEE.

Murat, NF, Mukhtar, WM, \& Menon, PS 2020, 'Enhanced $\mathrm{SPR}$ response using $\mathrm{Au} / \mathrm{GO}$ thin films via Kretschmann coupling by controlling the incident light intensities', Optoelectronics and Advanced Materials-Rapid Communications, vol. 14, pp. 482-486.

Ong, KS, Png, WH, Lin, HS, Pua, CH, \& Rahman, FA 2017 , October, 'Acoustic vibration sensor based on macro-bend coated fiber for pipeline leakage detection', in 2017 17th International Conference on Control, Automation and Systems (ICCAS) (pp. 167-171), IEEE.

Pechprasarn, S, Ittipornnuson, K, Jungpanich, T, Pensupa, N, \& Albutt, N 2019, 'Surface plasmon biosensor platform for food industry', in Applied Mechanics and Materials (vol. 891, pp. 103-108), Trans Tech Publications Ltd.

Rashid, ARA, Hakim, AAN, Yahaya, N, \& Surani, AH 2020, 'U-bent polymer optical fiber (POF) for Escherichia coli detection', Optoelectronics and Advanced Materials-Rapid Communications, 14 (March-April 2020), pp. 118-122.

Samsuri, ND, Mukhtar, WM, Rashid, ARA, Dasuki, KA \& Yussuf, AARHA 2017, 'Synthesis methods of gold nanoparticles for Localized Surface Plasmon Resonance (LSPR) sensor applications', in EPJ Web of Conferences (vol. 162, p. 01002), EDP Sciences.

Semeano, AT, Maffei, DF, Palma, S, Li, RW, Franco, BD, Roque, AC, \& Gruber, J, 2018 'Tilapia fish microbial spoilage monitored by a single optical gas sensor', Food Control, vol. 89, pp. 72-76.

Smith, ND, \& Sharp, JS 2017, 'Accessible biometrics: a frustrated total internal reflection approach to imaging fingerprints', Science \& Justice, vol. 57, no. 3, pp. 193-198. Sugito, H, \& Firdausi, KS, 2018, 'Design of integrated polarizer to evaluate quality of cooking oil based on the fluorescence polarization method', Journal of Physics and Its Applications, vol. 1, no. 1, pp. 28-31.

Surtono, A, Apriliana, P, Supriyanto, A, Pauzi, GA, Junaidi, J, Suciyati, SW \& Warsito, W, 2018, August, 'Measuring of Cassava starch content by using strain gauge sensor', in The 2nd International Conference on Applied Sciences Mathematics and Informatics.

Usha, SP, Shrivastav, AM, \& Gupta, BD 2016, 'FO-SPR based dextrose sensor using $\mathrm{Ag} / \mathrm{ZnO}$ nanorods/GOx for insulinoma detection', Biosensors and Bioelectronics, vol. 85, pp. 986-995.

Wang, Q, \& Wang, BT 2018, 'Surface plasmon resonance biosensor based on graphene oxide/silver coated polymer cladding silica fiber', Sensors and Actuators B: Chemical, vol. 275, pp. 332-338.

Zhao, Y, Lei, M, Liu, SX, \& Zhao, Q 2018, 'Smart hydrogelbased optical fiber SPR sensor for $\mathrm{pH}$ measurements', Sensors and Actuators B: Chemical, vol. 261, pp. 226-232. 